\title{
Forum
}

\section{Old people as users and consumers of healthcare: a third age rhetoric for a fourth age reality?}

\author{
CHRIS GILLEARD* and PAUL HIGGS $\dagger$
}

\begin{abstract}
This paper is concerned with the emergence of consumerism as a dominant theme in the culture surrounding the organisation and provision of welfare in contemporary societies. In it we address the dilemmas produced by a consumerist discourse for older people's healthcare, dilemmas which may be seen as the conflicting representations of third age and fourth age reality. We begin by reviewing the appearance of consumerism in the recent history of the British healthcare system, relating it to the various reforms of healthcare over the last two decades and the more general development of consumerism as a cultural phenomenon of the post World War II era. The emergence of consumer culture, we argue, is both a central theme in post-modernist discourse and a key element in the political economy of the New Right. After examining criticisms of post-modernist representational politics, the limitations of consumerism and the privileged position given to choice and agency within consumerist society, we consider the relevance of such critical perspectives in judging the significance of the user/consumer movement in the lives of retired people.
\end{abstract}

KEY WORDS - Consumerism, older people, healthcare policy, third age, post-modernism.

\section{Introduction}

This paper addresses the topic of consumerism as a dominant theme in the culture and provision of welfare in contemporary societies, and its significance for older people both as users and potential users. Traditionally, older people as patients and clients of health and welfare services have been treated as passive and grateful (Breemhar et al.

* Department of Psychology, Springfield University Hospital.

$\uparrow$ Academic Department of Psychiatry, University College Medical School. 
I990). This led to concerns being raised about the treatment of older people (Townsend i 662 ) and the appropriateness of the services that were provided. In the reformed world of health and welfare 'social markets', the rise of the idea of 'patients coming first' and that of clients being 'consulted for their real needs' has radically altered the way that policy makers and professionals see their tasks. New accountabilities and new ways of describing their activities have led to an awareness of the importance of the patient/client as consumer. While these changes have their origins in political ideology, they also reflect some of the changes seen in the modern world, most notably growing material affluence and lifestyle consumerism. In relation to older people, we would argue that it is upon such affluence that the reality of 'third ageism' is based and hence it is 'third agers' who are most likely to benefit from the consumerist approach to healthcare.

The theory of the third age as outlined by Peter Laslett (I 989) seeks to promote later life as a period of agentic self-fulfilment which he describes as the 'crown of life', freeing individuals to pursue their own projects and plan their own lives. However, as critics have pointed out (e.g. Bury i 995), they can only do so from the vantage point of physical and material well-being. In effect the third age is purchased and consumed as are other lifestyle choices. In the area of welfare this agentic third age perspective contributes to the growing emphasis placed upon 'the user's voice' and the need for older people to assert themselves. While such developments might seem to offer the prospect of a more responsive healthcare system, the fundamental imbalance in power between the public presenting as 'patients' and the managers and providers of publicly funded healthcare, remains unaltered. The rhetoric of consumerism attributes to all older people a position of agency which, as users of scarce and targeted resources, they cannot fill. Chronic illness and material impoverishment characterise the fourth age and turn older people into 'users'. This is a position from which no power of any kind can be exercised.

At the same time, the increasing use of such discourses within healthcare parlance confers a simulation of agency, shaping and influencing the language and behaviour of those who provide healthcare. While we would argue that the underlying motif of a consumerist ideology in healthcare derives from a New Right belief in the economic virtue of shifting responsibility from the state towards the individual and family, the discourse created to legitimate this renegotiated relationship between citizen and the state, reinforces an emerging culture of representation which affects both the public and the managers and providers of welfare. It offers the possibility of a 
service more personally satisfying than any that has emerged from a universally-provided but dependency-inducing system. The historical and material origins that have created this consumerist ideology of healthcare need to be understood, however, before one can consider what may become realisable from this newly emerging culture of welfare.

To provide the historical context of our position, we begin by reviewing the appearance of consumerism and the user movement in the recent history of the British healthcare system over the last two decades. We seek to place this within the more general development of consumerism as a cultural phenomenon of the post World War II era. Noting some of the earlier critics of consumerism, we consider the reemergence of consumer culture both as a central theme in postmodernist discourses and as a key element in the political economy of the New Right. We address the concerns of the critics of post-modernist ideology, noting the limitations of consumerism and the privileged position given to choice and agency within consumerist society, and the relevance such critical perspectives have in appraising the significance of the user/consumer movement in the lives of retired people. We conclude by recognising the iconic value of third age consumerist strategies in helping shape emerging forms of healthcare and the potential relevance this may have for a fourth age constituency.

\section{The new consumerism in healthcare}

The National Health Service and Community Care Act (Department of Health I990), gave a powerful impetus to the user movement in healthcare through the creation of quasi-markets. The principal intention behind the Act was to separate the responsibility for providing healthcare services from the responsibility of purchasing such care. This responsibility was retained by slimmed-down local health authorities who were re-invented as, in some sense, the collective representation of the 'purchasing power' of the local population. The accountability of the health authorities to the state, however, was unaltered. Providers were to remain the hospitals and clinics whose professional structures had dominated 2oth century healthcare but who now found themselves under contract to the purchasers of public health.

In exercising their role as purchasers of health for their local communities, health authorities were expected to consult the public; to survey their needs; to seek their views; to represent their aspirations. They became, in a fashion, the voice of the people, a people represented 
as potential patients or users of the services. Of course the local population had no real remit to determine the nature of this corporate representation of their potential 'patienthood', nor had they any means of determining the amount that they chose to spend on the services they might come to need in their future role as users. The abolition of local representation on District Health Authorities (DHAs) had seen to that. Nevertheless, the local population was the notional reference point for the decisions made about local healthcare, and the users' voice became a more frequently cited point of reference in the discourses about healthcare. This voice was to be sought out, recognised and reified in the debates about health services. Our argument is that it is a voice constructed by those who purchase, not for the people, but on behalf of the state. By promoting a consumerist perspective within health and social care, government has effectively shifted the responsibility for ensuring a satisfactory service away from the state to the 'virtual' individual. Providers of health and social care are seen as competing within a market for customers. Criticisms of the standards of service received are seen as customer complaints rather than political criticisms. In order to democratise this perspective every service user has to be credited with an equal voice. While those individuals with real purchasing power can exercise choice between competing providers in the private health and social care market, those without such power are offered charters, proxies and advocates, empty guarantees without any real means of redress in the civil courts (Coote i 992).

Older people represent the biggest group amongst the many impoverished groups of consumers of health and social care. Attempts to 'give them a voice', or to 'empower them' to be more effective consumers, figure prominently on the social policy agenda and seem to be favoured by the liberal research community. While such discourse may seem to offer opportunities for a shift in power from those who provide to those who receive services, the very constructed nature of this voice belies its intent. The current developments in consumerist discourse in the health and welfare field must be placed in the context of the evolution of welfare systems within the United Kingdom.

\section{The origins and evolution of the welfare state}

The launching of the British welfare state was undertaken as an administrative task to bring into being a modern nation that was protected from the social conflict of the inter-war years (Marshall i 992; Timmins I 996). In response to the challenge of post-war reconstruction, 
social policy was directed towards the elimination of what Beveridge termed 'the five giants': want, disease, ignorance, idleness and squalor (Beveridge 1942). These policies originated in wartime committees established by a government of national unity concerned with creating a sense of social citizenship that would provide the motivation for fighting and winning the war (Middlemas i979). The need for such social policies stemmed from the fact that, from its beginnings, the Second World War was seen as a 'people's war' involving mass mobilisation, conscription and the military targeting of the civilian population.

The popular desire for social reform that these plans reflected, and even inspired, was demonstrated in the landslide victory of the Labour Party at the i 945 general election. The military victory achieved by the nation was to be carried forward by 'winning the peace', through the implementation of large-scale nationalisation and the creation of national welfare institutions replacing the fragmentary social institutions of the pre-war era. As Marshall argued in his conception of citizenship, these rights included the entitlement to share in the wealth of civilisation (Marshall i 992). The citizen that would emerge would freely give allegiance to the nation because the nation would provide individuals with the opportunities to prosper, whilst protecting them from the unforeseen dangers of market capitalism.

The social citizenship embedded in the welfare state presupposed a benevolent relationship between the state and the individual-as Le Grand (I997) describes it, treating the citizen as a 'knight' not a 'knave'. Because of the universalism of the welfare state, everybody was notionally in the same position. There was little sense of differential entitlement. There was limited scope for consumerism in the market places of a war-ravaged Europe. Most people's daily experience of living with rationing provided little experience of, and exposure to, the choice and variety of goods and services that characterise consumerism. Ration cards shaped people's consumption in a manner not dissimilar to the way that the institutions of the welfare state shaped their expectations about education, work, housing, health and family support. A common consensus was established by the civil servants of the new post-war Britain (Timmins I 996).

As rationing was replaced by a growing array of goods in the shops and stores, this consensus began to fragment. The success of the postwar policies in creating full employment led to a population whose younger members in particular found themselves with both the time and money to spend. The media and media culture began to take over as a unifying influence. But the voices on radio and television no longer 
were provided by sole courtesy of the British Broadcasting Corporation. Independent television, and later, independent (pirate) radio, challenged the safe and secure tones of the BBC. The paternalism inherent in much of the welfare state become more evident when voiced by a Conservative rather than a Labour government. The common civic virtues of the post-war society were seen as flawed in the lives of those who wielded power. The desire for change, and the wish to break out of the moral and civic consensus of national unity, erupted in the i 960 s when youth became a privileged voice, denouncing the complacency of the past and looking toward a new and different future.

The conscious challenging of traditional authority, not only between classes but also within them, was a pervasive feature of the period. But the challenges of the rg6os rarely threatened the social institutions established by the welfare state. The Labour Party, returned to power in the I 960 s, promised greater change and greater modernisation. The 'white heat of technology' announced by Harold Wilson's government would lead to wider choices, greater opportunities and the further expansion of health, education and welfare. Greater choice and a better deal for citizens remained on the agenda. Then, in the early i 970 , the credit of the nation state began to wear thin.

The experience of more choice and increasing benefits did not suddenly disappear after the 1973 oil crisis, but the crisis brought about a growing questioning of the state's power to engineer a developing economy, one that could both provide for and protect all its citizens. In I 976 it was a Labour prime minister who told his party:

We used to think that you could just spend your way out of a recession and increase employment by cutting taxes and boosting government spending. I tell you in all candour that option no longer exists. (James Callaghan, cited in Gould i 993: 95)

The state was seen as reaching its limits. Calls for de-nationalisation of much of British industry began to be made. The welfare/well-being aspirations of the post-war flower-power/hippie generation were beginning to fray, just as the flares and the floral wear of fashion were being discarded and replaced by the ripped awkwardness of Punk. The welfare state was no longer the guarantor of profit and plenty. Increasingly it was perceived as putting a brake on economic productivity, and as justifiable only on the principles of public security and public protection (Mishra i984: 19-20).

Several reforms of the major social institutions of the British welfare state followed in the i 970 . The NHS in particular underwent various significant developments, including a more 'managed' system of 
strategic planning arising from the creation of Regional Health Authorities, Area Health Authorities, Family Practitioner Committees and Community Health Councils (Holliday ig92: ro). Although this process can be seen as the culmination of the centralised planning of welfare, the simultaneous introduction of the CHCs (Community Health Councils) offered the beginnings of a new system of accountability lying outside the control of the state professionals and the state civil servants. The demands for a 'patient's voice' had been evident in a number of government reports and party manifestos in the I 970 (Klein I983: 107) and, as the crises over public expenditure mounted, so the users' voice became of increasing significance.

\section{The growth of the users' voice in health and welfare}

The patient's voice was only partially represented in the CHCs. While half the membership was to be nominated by the local council, only one-third were nominees of voluntary organisations representing patients' views (Klein and Lewis I976). In effect, they were set up as relatively passive bodies with little more than an advisory influence over the existing health authorities. Within the bureaucracy of the multi-tiered health service, there was little prospect of them exercising any real user influence. Meantime the reforms introduced in the I970s were failing to cope with the changes of that decade. As constraints upon public expenditure became the order of the day and as the national economy faltered, lagging further and further behind in an already sluggish world economy, the health service was subjected to greater and greater pressure from both public and healthcare professionals.

It was only following the first 'Griffiths Report' in i983, outlining a revised management structure for the NHS, that an explicit statement was made to give real influence to users/consumers. Griffiths stressed the need to:

ascertain how well the service is being delivered ... by obtaining the experience and perceptions of patients and the community (Griffiths I983: 8)

The election of the new Conservative government of Margaret Thatcher marked a re-negotiation of the relationship between the government and the citizen. From the r 980 s onwards there was to be a real change in the nature of the social institutions that constituted the welfare state. An important element in their redefinition was the desire to see services organised around a 'responsiveness' to consumer 
demand based upon individual need. This was accompanied by a radical re-interpretation of welfare from universal, accessible, stateprovided benefits, to a limited commitment for more rudimentary levels of support targeted by the state towards its 'neediest' citizens. In the ig9os, following the second Griffiths report into community care ( 1988 ) and the government's own review of the health service, Working for Patients (DOH I 989), these ideas were extended to provide the basis for forms of managed competition where service users (managers as well as clients) could choose those service providers who could best meet their needs. The language of welfare underwent a transformation which changed the way both patients, clients, and professionals saw each other. In short, citizens were given consumer rights - and consumer responsibilities.

The term used to underpin this interest in users' voices was 'empowerment'. Empowerment came to embody a notion of consultation with groups traditionally excluded from dialogues about health. Employed with flexibility to the point of becoming anodyne, this term was used to describe each and every strategic development in the deployment of healthcare resources. User empowerment and the user's voice were ascribed the highest of priorities. Stakeholders' conferences, patients' councils and user groups were brought into existence and given a 'leading role' in health service planning.

Representation had to be demonstrably extensive and wide ranging. Surveys were conducted on issues such as rationing, and public preferences for healthcare provision. These 'public health' surveys did not stop at merely seeking the voice of the local population. They also established an individual reflexivity so that, in the process of being questioned, members of the public were taught to question themselves about their own (un)healthy lifestyles (Ogden ig95). Users could be losers too, as the focus shifted from a concern with meeting needs to a concern over managing risk. Those versions of the user's voice which are re-presented as needs appear only when professional strategies can be constructed to meet them. Re-presented as risk, they change the emphasis to one of caveat emptor, shifting the responsibility for health from the corporate representation of the people's needs to the individual's responsibility to preserve his or her own health (Nettleton I 997). Both the questions and the answers of each survey, focus group and consultation exercise, remain the textual property of the professional groupings the state has entrusted to deal with the governance of health.

This consumerist discourse has become insistent and pervasive. Representation is a required if not essential element of all aspects of 
healthcare, extending to those occupying the most marginal positions in the health system. People with severe dementia, people with profound sensory and mental disabilities, who traditionally have been the recipients of institutionalised care, are expected to voice their preferences. Strenuous attempts are made to construct a voice for those whose actions are normally the focus of surveillance, interpretation and modification. No apparent mental or physical barrier is to be acknowledged in the pursuit of the authentic voice of the user. The moral authority vested in user representation cannot be directly challenged although it can be modified and often is. Once more we discover the interpretation of the experts lying at the heart of the process. Whilst the patients may seem free to set the agenda, the manner in which that agenda becomes incorporated into the structures of power and provision remains firmly in the hands of the authorities.

Researchers are themselves caught up in the same processes of interpretation and reification. In the field of 'deep' old age, there is an evident desire to demonstrate that people with severe dementia are capable of articulating a meaningful discourse about their healthcare needs and expressing approval and disapproval of the practices to which they are subject. Researchers such as Kitwood have developed interpretative texts from which to construct signifiers of well-being amongst demented elderly people living in institutional settings (Kitwood and Bredin I992). Sabat and Harré (1992) provide an interpretative model to 'de-construct' the conversations they themselves have initiated with patients suffering from Alzheimer's disease. Action research projects have sought to establish a technology of 'citizen advocacy' for older people, as a way of lending others' voices to compensate for the lack of power of the user's own (c.f. Wertheimer I993; Dunning 1995). The manner in which this voice is to be represented, however, requires the technical expertise of those whose task it is to interpret the culture of health and welfare.

A particularly clear example is Goldsmith's book, disingenuously titled Hearing the Voice of People with Dementia. The book purports to provide accounts of what people with dementia can or want to communicate or how they feel or understand their condition, derived from 'over two hundred written replies (sic) from over a thousand nominated people invit[ed] to make comments' - together with 'six indepth interviews with people with dementia' (Goldsmith i 996). The bulk of the book is constructed around the written comments from the myriad interpreters of these 'absent consumers'. The six people with dementia mentioned in the introduction seem totally submerged within this expert discourse. Such research/practitioner approaches seem to 
do little more than create a hall of mirrors, out of which proxy purchasers and proxy patients seek to shape the services that providers offer to patients whose position, in so far as it can be ascertained, remains 'passive, accepting, patient and grateful' (Baldock and Ungerson I996). Just as the voice of the person with dementia can be 'appropriated and endowed with meaning by those surrounding the dementing (person)' (Golander and Raz i 996: 283), so more generally the voices of users, carers, consumers and all others possessed of a chartered right to healthcare, can be endowed with other meanings. By first interpreting and incorporating the consumers' voice into the state's health and welfare systems, the state can represent itself as the supporter of individual choice and consumer sovereignty, while divesting itself from as much communal and statutory responsibility as possible.

Giving a voice to those not normally known for voicing their concerns is part of the rhetoric of modern society and its systems of governance. In place of public action, we have public consultation. Concerns are addressed but no guarantees given of any action. The recent Carers' (Recognition and Services) Act (DOH i 995) exemplifies this point. Carers are 'recognised', there needs acknowledged, their voices heard. Nothing more substantive is required. This appears a perfect piece of post-modernist policy making. Everybody's position is taken into consideration and at no additional cost. It appears as if the text is all: inclusive, democratic and empowering and, at the same time, empty of practical significance.

For a minority, the opportunity provided by the rhetoric of consumerism does offer something real. A market in private health insurance has been stimulated, and financial planning can mean an alternative to the uncertain future of structured dependency in the state's hospitals and rest homes. But it is the active, agentic third agers who are best placed to shop around for personal care policies and it is the active, agentic third agers who form the membership of associations representing consumerist perspectives. Third agers are frequently represented in carers' organisations (e.g. Alzheimer's Disease Society, MENCAP, National Schizophrenia Fellowship, Parkinson's Disease Society and SCOPE) whose task is to advocate for greater resources to be set aside for their own needs as carers. But the vast majority of consumers deep in their old age remain the subjects of others' language, their desires submerged beneath their accumulated disabilities while their needs are constructed by others (whether through professional or voluntary 'advocates' or simply arrived at through the actuarial logic of assessment). 


\section{Consumerism as a cultural ideology}

The significance of the idea of the consumer in modern society has been documented by many commentators (Ewen i 976; McKendrick et al. ı 982; Featherstone I983; Miller ı 987; Baudrillard ı988; Bauman I987, г 988). One key feature, drawn out particularly by Keat et al. ( I994) is the seeming shift in power from the producers of goods and services to those who consume them. The idea of 'consumer sovereignty' is embedded in the free market model of economic relationships, whereby producers' success or failure depends upon their ability to meet the demands and desires of the consumer. In this model it is the actions of individuals as consumers that are said to dictate the type and quality of the goods and services that can be produced. Applied to the social market this argument suggests that the authority previously invested in the professionals responsible for producing health and social care - the doctors, nurses, social workers and care officers - is diminished as the users of those services are granted 'consumer power'. This viewpoint is exemplified in Donabedian's remark that the 'ultimate validator' for the success of healthcare is in achieving patient/client satisfaction (Donabedian i 966). By equalising the relationship between producer and consumer it is assumed that a degree of democratisation can be achieved such that individuals as consumers can become, in Miller's terms, 'the vanguard of history' (Miller I995). However, as Bauman (I988) has cautioned, consumerism is a two-edged sword - those in subordinate positions in the market can feel themselves placed at considerable disadvantage compared with those who are better off.

This polarisation of consumer society between those empowered to choose and those whose choices are restricted to the bare essentials of social reproduction, can be seen in the division that exists between third and fourth agers. Indeed it is possible to argue that one of the key distinctions between third and fourth agers lies precisely in their access to the means of consumption. If, as some have argued, the relationship between user and producer is in the power to control the meaning of the exchange (Abercrombie I994), the ability to present oneself as a consumer of health or social care - and to carry off that encounter on such terms - requires that the producers and consumers are socialised by the same rhetoric ('culturally drenched' in another context - see Featherstone I99I), and that the consumer can be credited with possessing agentic powers. The failure of the consumer to exhibit any obvious characteristics of agency creates a dissonance for the provider, limiting his or her ability to act as if the patient did. The consequence 
is either a shallow tokenism of consultation or a cynical disregard for the values that such a perspective is meant to engender.

Attempts to create a consumer culture within the health and welfare services have been most evident in the concept of 'consumer directed' personal assistance models expounded by the independent living and disability rights movements in the United States:

Consumer-directed modes of financing and delivering attendant services permit service recipients - as opposed to medical or social work professionals - comparatively greater choice and control over all aspects of service provision, from hiring the attendant to defining the attendant's duties...and..deciding how specific tasks or services are performed (Doty et al. 1996).

A similar model can be seen in the Independent Living Foundation's allowance to disabled people under 65 years of age in the UK. Such approaches require a deal of confidence that the disability rights movement seeks to develop. It is of obvious significance that an age barrier already qualifies this representation.

The fourth ager lacks this authority of consumption. Whether through failing mental powers, poverty or bodily decrepitude, they are unable to resist the meanings attributed to their presence within the health or social care arena. For these fourth agers the discourse of consumerism offers a false dawn to their liberation from the embrace of dependency culture, just as the universalism of the welfare state failed in the end to guarantee protection to all from the unintentional cruelties of the market. Lacking the material and cultural capital required of the sovereign consumers, inadequately socialised into the discourse of the social market, their 'views' are present only in the competing voices of professionals, managers, voluntary agencies and variously appointed citizen advocacy groups who now occupy the representational spaces created by the growing retraction of the public sector (Clarke i 996).

\section{Post-modern politics, post-modern rights?}

Writers locating themselves within a post-modern approach argue that the processes responsible for endowing the users' voices with significance can themselves be re-shaped by the very voice they have created. This point is made by Ryan in his review of post-modern politics:

representations can create the substance they supposedly reflect. This can be looked at in two ways - either as a movement toward artifice, informationalism 
and a techno-culture of entirely simulated realities... or as a movement with progressive possibilities that signals the ability to reshape the supposedly immovable (Ryan I988: 560).

Supporters of a post-modernist politics claim that representing the person as consumer enables a shift in authority to take place, from the professionals in the health and social care system to the patients or clients themselves, such that:

expertise carries less weight, deference is less marked... and... even the legal powers effectively deployed by ... doctors or social workers are undermined (Abercrombie i 994: 53).

Consumer sovereignty can be viewed critically or ironically as little more than a gloss to cover the inequalities of production. But the attribution of agency itself can have real effects - both on those making the attributions as well as on those for whom such attributions are made (see Gabriel and Lang I996). Possession of an identity as a user/consumer has come to play an increasing part in the discourse of late 20 th century welfare politics. Groups previously marginalised by their exclusion from the main productive forces in society by impairment, disability or handicap are seen as having a legitimate right to express their own needs (Campbell and Oliver i 996) even if, as in the case of people with dementia, this presents difficulties in the rational discourse of service provision. The questions that arise are whether real improvements can be achieved in the lives and material circumstances of fourth agers on the basis of such representations, cultural texts and deliberate reconstructions; whether by drenching the producers as well as the consumers in the cultural ideology of choice and empowerment, it will prove possible to eradicate or at least reduce those practices which belittle and confine disabled and disadvantaged citizens. In short, whether the language of consumerism can prove transforming not only of the activities of caring but of the very nature of the relationship between carer and cared for. The critic may consider the changes to be as ephemeral as the rhetoric from which they have come, ultimately determined by the level of financial resources available, leaving modern day fourth agers further betrayed by such language. On the other hand, if actions are structured by language, the emancipatory potential of consumerist rhetoric and user representation may help undermine the 'structured dependency' of the fourth age that modernisation has created. Rather than being concerned with questions of the authenticity of the user's voice, perhaps what we should look for are the processes whereby such perspectives can affect the policy and practices of healthcare provision. 


\section{Conclusions}

One of the powerful arguments in favour of accepting the postmodernisation of culture is the preponderance of discourses accounting for our day-to-day behaviour. The reflexivity of modern life inhibits the development of any dominant discourse and encourages the development of multiple identities and subjectivities. This does not stop attempts to weave these multiple positions into a single unifying voice. With the current emphasis upon users and the users' voice, health and social care policies are being articulated through processes of consultation which appear to be open, undetermined and enabling, but which nevertheless contain predetermined agendas and already decided strategies.

Language, or rather its form as text, has become the principal means of expressing and articulating power. It is the controlling medium through which welfare is organised, administered and shown to be effective. The language of the market is thrust into the mouths of citizens to sustain a 'hyper-reality' of user involvement and empowerment. Even those without a voice are expected to provide some input into this process, to express this common interpolation as consumer citizens. Such discourse is not of course without effect. User movements have sprung up in a number of modern states, seeking to obtain improvements in the practices of care. The providers of health and welfare are less sure of themselves and the services they provide. But the gap between text and practice which the modern state has created, ensures that making a real difference remains an elusive and possibly illusory goal. In real markets, consumers' ability to purchase goods and services makes them agentic where their wants and preferences can have real effects. This is the situation of those retired people with significant incomes who may be thought of as the archetypal 'third age constituency'. For those fourth agers without resources or who have made no provision for old age, their status as users provides them with little more than tokenistic consultation on the niceties by which they are treated. This is the distinction between a market and the marketing of services which contrasts the over-burgeoning of private sector health and social care agencies and the narrow targeting of what the public sector can offer.

In saying this, we do not believe this is a stable and permanent condition. Alongside the emphasis upon making private provision for one's future health and well-being, is a cultural process that creates the possibility of an avant-garde whose purchasing strategies can have iconic value in setting future agendas across the spectrum of care. This 
is the possibility of a third age voice being used for a fourth age constituency. Once the shift towards individualisation has occurred it is difficult to see a return to notions of collective and universal provision given the continuing fragmentation of lifestyles. The implementation of personal care plans cannot be re-written as a block contract however much in practice it may seem to be implemented as one. The 'pretence' of a voice can set up structures that are forced to take account of individuality however much they circumscribe it.

\section{References}

Abercrombie, N. i 994. Authority and consumer society. In Keat, R., Whiteley, N. and Abercrombie, N. (eds), The Authority of the Consumer. Routledge, London, 43-6I.

Baldock, J. and Ungerson, C. I996. Becoming a consumer of care: developing a sociological account of the 'new community care'. In Edgell, S., Hetherington, K. and Warde, A. (eds), Consumption Matters. Blackwell Publishers, Oxford.

Baudrillard, J. i 988. Selected Writings. Polity Press, Cambridge.

Bauman, Z. I987. Legislators and Interpreters: on Modernity, Post-modernity and the Intellectuals. Polity Press, Cambridge.

Bauman, Z. i988. Freedom. Open University Press, Milton Keynes.

Beveridge, W. Sir. 1942. Social Insurance and Allied Services. HMSO, London.

Breemhaar, B., Visser, A. and Kleijen, J. G. i 99o. Perceptions and behaviour among elderly hospital patients: description and explanation of age differences in satisfaction knowledge, emotions, and behaviour. Social Science and Medicine 3r, I $377-85$.

Bury, M. i 995. Ageing, gender and sociological theory. In Arber, S. and Ginn, J. (eds), Connecting Gender and Ageing. Open University Press, Buckingham.

Campbell, J. and Oliver, M. i 996. Disability Politics: Understanding our Past, Changing our Future. Routledge, London.

Clarke, J. i 996. Public nightmares and communitarian dreams: the crisis of the social in social welfare. In Edgell, S., Hetherington, K. and Warde, A. (eds), Consumption Matters. Blackwell Publishers, Oxford.

Coote, A. I992. Introduction. In Coote, A. (ed), The Welfare of Citizens: Developing New Social Rights. Rivers Oram Press, London, I-I4.

Department of Health. I989. Working for Patients. HMSO, London.

Department of Health. i99o. National Health Service and Community Care Act, I9go. HMSO, London.

Department of Health. 1995. Carers (Recognition and Services) Act 1995. HMSO, London.

Donabedian, A. ig66. Evaluation of the quality of medical care. Millbank Memorial Fund Quarterly Bulletin 44, i66-80.

Doty, P., Kasper, J. and Litvak, S. i 996. Consumer-directed models of personal care: lessons from Medicaid. Millbank Quarterly Bulletin 74, 377-409.

Dunning, A. i 995. Citizen Advocacy with Older People: a Code of Good Practice. Centre for Policy on Ageing, London.

Ewen, S. 1976. The Captains of Consciousness: Advertising and the Social Roots of Consumer Culture. McGraw-Hill, New York.

Featherstone, M. I983. Consumer culture: an introduction. Theory, Culture and Society, I, $4-9$.

Featherstone, M. I99 I. Cited in Abercrombie, N. I994, 52. 


\section{Chris Gilleard and Paul Higgs}

Gabriel, Y. and Lang, T. i 996. The Unmanageable Consumer. Sage Publications, London.

Golander, H. and Raz, A. E. I996. The mask of dementia: images of 'demented residents' in a nursing ward. Ageing and Society, I6, 269-87.

Goldsmith, M. I996. Hearing the Voice of People with Dementia: Opportunities and Obstacles. Jessica Kingsley Publishers, London.

Gould, A. 1993. Capitalist Welfare Systems: a Comparison of Britain Japan and Sweden. Longman, London.

Griffiths, R. I983. NHS Management Enquiry Report. DHSS, London.

Griffiths, R. i 988 . Community Care: Agenda for Action. HMSO, London.

Holliday, I. i 992. The NHS Transformed. Baseline Books, Manchester.

Keat, R., Whiteley, N. and Abercrombie, N. (eds), i 994. The Authority of the Consumer. Routledge, London.

Kitwood, T. and Bredin, K. I992. Toward a theory of dementia care: personhood and well-being. Ageing and Society, 12, 269-87.

Klein, R. I983. The Politics of the National Health Service, Longmans, London.

Klein, R. and Lewis, J. I 976. The Politics of Consumer Representation. Centre for Studies in Social Policy, London.

Laslett, P. 1989. A Fresh Map of Life: the Emergence of the Third Age. Weidenfield and Nicholson, London.

Le Grand, J. i 997. Knights, knaves or pawns? Human behaviour and social policy. Journal of Social Policy, 26, I 49-69.

Marshall, T. H. i992. Citizenship and Social Class. Pluto Press, London.

McKendrick, N., Brewer, J. and Plumb, J. H. ig82. The Birth of a Consumer Society. Europa, London.

Middlemas, K. I979. Politics in Industrial Society: the Experience of the British System since I9II. Andre Deutsch, London.

Miller, D. i987. Material Culture and Mass Consumption. Blackwell, Oxford.

Miller, D. I 995. Consumption as the vanguard of history. In Miller, D. (ed), Acknowledging Consumption. Routledge, London, I-57.

Mishra, R. I 984. The Welfare State in Crisis. Harvester Wheatsheaf, Hemel Hempstead.

NHS Executive. 1996. Patient Partnership: Building a Collaborative Strategy. NHS Executive, Leeds.

Nettleton, S. i 997 . Governing the risky self: how to become healthy wealthy and wise. In Petersen, A. and Bunton, R. (eds), Foucault, Health and Medicine. Routledge, London.

Ogden, J. i 995. Psychosocial theory and the creation of the risky self. Social Science and Medicine, 40, 409-15.

Ryan, M. i 988. Post-modern politics. Theory Culture and Society, 5, 559-76.

Sabat, S. and Harré, R. i 992 . The construction and deconstruction of self in Alzheimer's disease. Ageing and Society, I2, 443-6 I.

Timmins, N. I996. The Five Giants: a Biography of the Welfare State. Fontana, London.

Townsend, P. ig62. The Last Refuge. Routledge and Kegan Paul, London.

Wertheimer, A. I993. Speaking Out: Advocacy and Older People. C.P.A. Report 19, Centre for Policy on Ageing, London.

Address for correspondence:

Accepted I9 November 1997

Chris Gilleard, Department of Psychology, Springfield University

Hospital, Tooting, London, SW I 7 7DJ 